Editor's Note: These short reviews of recent JNeurosci articles, written exclusively by students or postdoctoral fellows, summarize the important findings of the paper and provide additional insight and commentary. If the authors of the highlighted article have written a response to the Journal Club, the response can be found by viewing the Journal Club at www.jneurosci.org. For more information on the format, review process, and purpose of Journal Club articles, please see http://jneurosci.org/content/ preparing-manuscript\#journalclub.

\title{
Complement C3 Inhibition Modulates Neurodegeneration in Chronic Traumatic Brain Injury
}

\author{
ํㅣㄹ Mary Ellene Boulos ${ }^{1,2}$ and $@$ Michael Johnathan Charles Bray ${ }^{1,3}$ \\ ${ }^{1}$ University of Toronto and Cognitive Neurorehabilitation Sciences Laboratory, Toronto Rehabilitation Institute, University Health Network, Toronto, \\ Ontario M5G 2A2, Canada, ${ }^{2}$ Rehabilitation Sciences Institute, and ${ }^{3}$ Institute of Medical Science, University of Toronto \\ Review of Alawieh et al.
}

Traumatic brain injury (TBI), caused by an exertion of forces to the head, involves immediate structural damage followed by neuropathological cascades, which may include degeneration (Green et al., 2014; Hammad et al., 2018). Chronic neuroinflammation is an important driver of ongoing neurodegeneration observed after injury, contributing to secondary cell death and tissue damage associated with persistent deficits (Morganti-Kossmann et al., 2002; Van Beek et al., 2003; Johnson et al., 2013; Lozano et al., 2015). Therefore, studying neuroinflammation in TBI is essential to understanding its degenerative pathology.

Because of its prominent role in neuroinflammatory processes, the complement system may be an important contributor to neurodegeneration after TBI (Hammad et al., 2018). The complement system, a component of the innate immune system, comprises $>30$ zymogens (enzyme precursors), which are activated sequentially in the presence of antigens, such as foreign pathogens or cellular debris. The complement cascade

Received April 18, 2018; revised July 9, 2018; accepted July 19, 2018.

We thank Dr. Robin E.A. Green (Toronto Rehabilitation Institute), Bhanu Sharma (McMaster University), and Anisa Morava (Western University) for comments and guidance in the preparation of the manuscript.

The authors declare no competing financial interests.

Correspondence should be addressed to Mary Ellene Boulos, Toronto

Rehabilitation Institute, 550 University Avenue, Room 11-207, Toronto, Ontario M5G 2A2, Canada.E-mail: mary.boulos@mail.utoronto.ca.

DOI:10.1523/JNEUROSCI.1011-18.2018

Copyright $\odot 2018$ the authors $\quad 0270-6474 / 18 / 387201-03 \$ 15.00 / 0$ can be activated simultaneously through three known pathways: the classical pathway, the lectin pathway, and the alternative pathway. The classical pathway is activated by the formation of antigen-antibody complexes. This subsequently initiates the binding of zymogen C1q to the antigen-antibody pair. This complex in turn cleaves complement $\mathrm{C} 2$ into $\mathrm{C} 2 \mathrm{a}$ and $\mathrm{C} 2 \mathrm{~b}$, and cleaves $\mathrm{C} 4$ into C4a and C4b. The C4bC2b complex then cleaves $\mathrm{C} 3$ into $\mathrm{C} 3 \mathrm{a}$ and $\mathrm{C} 3 \mathrm{~b}$. C3a and C3b play important roles in immune activation and neuroinflammation. Specifically, C3a is an anaphylatoxin that increases vascular permeability, smooth muscle contraction, and histamine release from mast cells, whereas C3b is an opsonin that increases phagocytic activity of macrophages, including microglia (Zabel and Kirsch, 2013). The lectin pathway is activated by different antigens than the classical pathway, but it involves the same downstream signaling cascade leading to the generation of $\mathrm{C} 3 \mathrm{a}$ and C3b. The alternative pathway, in contrast, is not directly activated by antigens; rather, it is constantly active at a low level, with the downstream, inflammatory cascade initiated by spontaneous hydrolysis of $\mathrm{C} 3$ into $\mathrm{C} 3 \mathrm{a}$ and $\mathrm{C} 3 \mathrm{~b}$. C3b can subsequently bind to factor $\mathrm{B}$ fragment $\mathrm{Bb}(\mathrm{fBb})$, forming the alternative $\mathrm{C} 3$ convertase, $\mathrm{C} 3 \mathrm{bBb}$. The $\mathrm{C} 3$ convertases of all three pathways can lead to cleavage of C5 to form C5a and C5b. C5a is an anaphylatoxin similar to $\mathrm{C} 3 \mathrm{a}$, but $\mathrm{C} 5 \mathrm{~b}$ binds to $\mathrm{C} 6, \mathrm{C} 7, \mathrm{C} 8$, and several $\mathrm{C} 9$ mole- cules to form the membrane attack complex (MAC). The MAC, produced by all three pathways, inserts into cell membranes, disrupting membrane integrity and other cellular processes (Hammad et al., 2018).

Recent studies have identified the $\mathrm{MAC}$ as a potential therapeutic target for mitigating early neuropathology in TBI. In animal models, MAC inhibition within a week of TBI reduced neuronal damage, microglial activation, neurological deficits, and neuronal death (Fluiter et al., 2014; Ruseva et al., 2015), attenuated the inflammatory response, and upregulated expression of genes associated with neuroprotection (Leinhase et al., 2007). The importance of complement in chronic neuroinflammatory changes after TBI remains to be elucidated, however. Compellingly, activation of the complement system triggers a cascade of pathophysiological events that have been implicated in the poor neural outcomes observed after TBI. These include the following: induction of neural apoptosis, neuronal death, and increased leukocyte infiltration into the brain accompanied by subsequent free radical-mediated oxidative stress (Longhi et al., 2009; Hammad et al., 2018). With growing consensus that neurodegeneration and behavioral deterioration occur in the chronic stages of TBI (Himanen et al., 2006; Green et al., 2014), and that neuroinflammation is a persisting consequence of TBI (Johnson et al., 2013), elucidation 
of underlying neuroinflammatory mechanisms implicated in these chronic deficits may help identify novel therapeutic targets.

Alawieh et al. (2018) recently investigated the role of complement in chronic neuropathological and behavioral outcomes after TBI. The authors subjected adult male mice to controlled cortical impact (CCI) to mimic TBI. Complement pathways were inhibited starting $1 \mathrm{~h}$ after CCI by administering CR2Crry (which inhibits all complement pathways), CR2fH (which inhibits the alternative complement pathway and C3 activation), or CR2CD59 (which inhibits MAC formation). Although all three inhibitors reduced deposition of terminal MAC, only CR2Crry and $\mathrm{CR} 3 \mathrm{fH}$ reduced deposition of C3d (a C3b breakdown product), allowing the authors to compare the respective roles of MAC and C3 in recovery and neurodegeneration. Mice were examined histologically at the chronic stages of injury, $30 \mathrm{~d}$ after CCI.

Alawieh et al. (2018) provided evidence that complement-mediated neuroinflammation is associated with degenerative changes observed in the chronic phase of TBI. Targeted inhibition of C3 activation reduced neuroinflammation relative to vehicle-treated control mice, in which neuroinflammation was increased, as indicated by accumulation of proinflammatory microglia and macrophages. Specific inhibition of MAC formation had no apparent effect on neuroinflammation compared with controls.

To assess whether C3 inhibition affected the neuroprotective response to injury, namely, neurogenesis and neuroblast migration, the migration rate of neuroblasts was measured. At $30 \mathrm{~d}$ CCI, neuroblast migration was not significantly different between vehicle controls and animals treated to inhibit MAC formation. In contrast, the number of neuroblasts migrating to the lesion site was significantly greater in C3inhibited mice, suggesting that neuroreparatory mechanisms were preserved by inhibiting C3 after TBI. Somewhat surprisingly, MAC inhibition was associated with significantly greater neurodegeneration and degenerative loss of neurons, greater complement deposition, and less elaborate dendritic arborization than mice treated with C3 inhibitors. These findings differ from previous studies that have linked MAC inhibition to improved recovery and reduced neuropathology after TBI (Fluiter et al., 2014). Perhaps accounting for this difference, studies linking MAC inhibition to improved neural outcomes examined animals in the acute temporal window, suggesting distinct roles for MAC at different time points during TBI recovery. The current study highlights the potential utility of targeted C3 inhibitors for modulating neurodegeneration while preserving the repair and regeneration mechanisms of the complement system.

To investigate contributions of the complement system to the substantial, persisting cognitive and motor impairments observed after TBI, Alawieh et al. (2018) examined cognitive and motor recovery after inhibiting the alternative complement pathway. C3 inhibition was associated with significantly improved spatial learning and retention, assessed using the Barnes maze 24-27 $\mathrm{d}$ after TBI. Compared with controls and animals treated with the MAC inhibitor, C3-inhibited mice had significantly faster learning curves and fewer errors during the acquisition and retention of spatial memory. These findings are consistent with previous research implicating greater dendritic arborization and neurogenesis in learning and memory, highlighting a role of neuroinflammation in cognitive deficits that occur after TBI (Ziv et al., 2006; Viggiano et al., 2018). In addition, C3 inhibition significantly increased motor scores on the ladder walking task and resulted in faster recovery compared with controls and mice treated with the MAC inhibitor. C3 inhibition also resulted in significantly reduced forelimb and hindlimb errors. Together, these findings implicate the complement pathway as a mediator of cognitive and motor dysfunction after TBI, with C3 inhibition resulting in improved cognitive and motor recovery compared with MAC inhibition alone.

Together, the findings by Alawieh et al. (2018) indicate that activation of C3 likely contributes to chronic, deleterious neural, cognitive, and behavioral outcomes that commonly occur after TBI. While previous studies have demonstrated an important role for MAC in acute neuroinflammation after TBI, Alawieh et al. (2018) found that inhibition of MAC did not significantly alter neuroinflammatory processes or motor and cognitive recovery in the chronic phase. In contrast, inhibition of $\mathrm{C} 3$ activation, which occurs upstream of MAC formation, led to significant reductions in neurodegeneration, along with increases in neuroblast migration and dendritic and synaptic density, as well as improved cognitive and motor recovery after TBI. These findings suggest that other complement activation products, such as anaphylatoxins (C3a, C5a) and op- sonins (C3b), might play an important role in neurodegeneration during the chronic stages of TBI. Namely, complement anaphylatoxins generate an inflammatory response in which neutrophils are recruited to the CNS, releasing nitric oxide synthetase resulting in neuronal death and subsequent neurodegeneration (Kulkarni et al., 2004). Moreover, complement opsonins promote activation of infiltrating immune cells, microglial phagocytosis, and synaptic clearance, which contribute to neuronal loss and neurodegenerative processes (Alawieh and Tomlinson, 2016). Thus, the expanded characterization of neuroinflammatory mechanisms by Alawieh et al. (2018) demonstrates the importance of targeting upstream complement components to maximally reduce degeneration and behavioral deficits in the chronic phase of TBI.

The findings of Alawieh et al. (2018) may be extended to provide insight into mediators of other chronic neurological changes following TBI. Relevantly, recent evidence has demonstrated that, after moderate to severe injury, ongoing volumetric decline of the hippocampal formation may be exacerbated by anxiety (Terpstra et al., 2017). Substantial psychological stress, a common feature of anxiety disorders in general, increases plasma concentrations of $\mathrm{C} 3$ and complement activation and is accompanied by an elevated inflammatory response (Burns et al., 2008; Vogelzangs et al., 2013). Considering the demonstrated importance of these neuroinflammatory processes in mediating chronic, neurodegenerative outcomes after TBI, the results of Alawieh et al. (2018) suggest a potential mechanism by which psychiatric health might influence functional and organic recovery after TBI. Future work into the influence of psychiatric status on TBI-associated neurodegeneration should focus on the role of complement systems and the potential of C3 inhibition in mitigating volumetric declines.

Through modulation of the complement system and C3 inhibition specifically, Alawieh et al. (2018) have provided expanded insight into the mechanisms underlying neuropathology and behavioral recovery after TBI. These findings challenge previous understandings of biochemical mechanisms responsible for neurodegenerative changes after TBI and highlight opportunities for clinical intervention. Furthermore, etiological insight regarding cellular drivers of degenerative change may have broad implications, advancing understandings of clinically observed mediators of neurodegeneration. 


\section{References}

Alawieh A, Tomlinson S (2016) Injury sitespecific targeting of complement inhibitors for treating stroke. Immunol Rev 274:270280. CrossRef Medline

Alawieh A, Langley EF, Weber S, Adkins D, Tomlinson S (2018) Identifying the role of complement in triggering neuroinflammation after traumatic brain injury. J Neurosci 38: 2197-2217. CrossRef Medline

Burns VE, Edwards KM, Ring C, Drayson M, Carroll D (2008) Complement cascade activation after an acute psychological stress task. Psychosom Med 70:387-396. CrossRef Medline

Fluiter K, Opperhuizen AL, Morgan BP, Baas F, Ramaglia V (2014) Inhibition of the membrane attack complex of the complement system reduces secondary neuroaxonal loss and promotes neurologic recovery after traumatic brain injury in mice. J Immunol 192:23392348. CrossRef Medline

Green RE, Colella BM, Maller JJ, Bayley M, Glazer JM, Mikulis DR (2014) Scale and pattern of atrophy in the chronic stages of moderatesevere TBI. Front Hum Neurosci 8:1-9. CrossRef Medline

Hammad A, Westacott L, Zaben M (2018) The role of the complement system in traumatic brain injury: a review. J Neuroinflammation 15:24. CrossRef Medline

Himanen L, Portin R, Isoniemi H, Helenius H, Kurki T, Tenovuo O (2006) Longitudinal cognitive changes in traumatic brain injury: a 30-year follow-up study. Neurology 66:187192. CrossRef Medline

Johnson VE, Stewart JE, Begbie FD, Trojanowski
JQ, Smith DH, Stewart W (2013) Inflammation and white matter degeneration persist for years after a single traumatic brain injury. Brain 136:28-42. CrossRef Medline

Kulkarni AP, Kellaway LA, Lahiri DK, Kotwal GJ (2004) Neuroprotection from complementmediated inflammatory damage. Ann N Y Acad Sci 1035:147-164. CrossRef Medline

Leinhase I, Rozanski M, Harhausen D, Thurman JM, Schmidt OI, Hossini AM, Taha ME, Rittirsch D, Ward PA, Holers VM, Ertel W, Stahel PF (2007) Inhibition of the alternative complement activation pathway in traumatic brain injury by a monoclonal anti-factor $\mathrm{B}$ antibody: a randomized placebo-controlled study in mice. J Neuroinflammation 4:13. CrossRef Medline

Longhi L, Perego C, Ortolano F, Zanier ER, Bianchi P, Stocchetti N, McIntosh TK, De Simoni MG (2009) C1-inhibitor attenuates neurobehavioral deficits and reduces contusion volume after controlled cortical impact brain injury in mice. Crit Care Med 37:659-665. CrossRef Medline

Lozano D, Gonzales-Portillo GS, Acosta S, de la Pena I, Tajiri N, Kaneko Y, Borlongan CV (2015) Neuroinflammatory responses to traumatic brain injury: etiology, clinical consequences, and therapeutic opportunities. Neuropsychiatr Dis Treat 11:97-106. CrossRef Medline

Morganti-Kossmann MC, Rancan M, Stahel PF, Kossmann T (2002) Inflammatory response in acute traumatic brain injury: a doubleedged sword. Curr Opin Crit Care 8:101-105. CrossRef Medline
Ruseva MM, Ramaglia V, Morgan BP, Harris CL (2015) An anticomplement agent that homes to the damaged brain and promotes recovery after traumatic brain injury in mice. Proc Natl Acad Sci U S A 112:14319-14324. CrossRef Medline

Terpstra AR, Girard TA, Colella B, Green RE (2017) Higher anxiety symptoms predict progressive hippocampal atrophy in the chronic stages of moderate to severe traumatic brain injury. Neurorehabil Neural Repair 31: 1063-1071. CrossRef Medline

Van Beek J, Elward K, Gasque P (2003) Activation of complement in the central nervous system. Ann N Y Acad Sci 992:56-71. CrossRef Medline

Viggiano D, Speranza L, Crispino M, Bellenchi GC, di Porzio U, Iemolo A, De Leonibus E, Volpicelli F, Perrone-Capano C (2018) Information content of dendritic spines after motor learning. Behav Brain Res 336:256260. CrossRef Medline

Vogelzangs N, Beekman AT, de Jonge P, Penninx BW (2013) Anxiety disorders and inflammation in a large adult cohort. Transl Psychiatry 3:e249. CrossRef Medline

Zabel MK, Kirsch WM (2013) From development to dysfunction: microglia and the complement cascade in CNS homeostasis. Ageing Res Rev 12:749-756. CrossRef Medline

Ziv Y, Ron N, Butovsky O, Landa G, Sudai E, Greenberg N, Cohen H, Kipnis J, Schwartz M (2006) Immune cells contribute to the maintenance of neurogenesis and spatial learning abilities in adulthood. Nat Neurosci 9:268275. CrossRef Medline 